\title{
Photovoltaic Energy Conversion System Constructed by High Step-Up Converter with Hybrid Maximum Power Point Tracking
}

\author{
K. I. Hwu, W. C. Tu, and C. R. Wang \\ Department of Electrical Engineering, National Taipei University of Technology, No. 1, Section 3, Chung-Hsiao E. Road, \\ Taipei 10608, Taiwan \\ Correspondence should be addressed to K. I. Hwu; eaglehwu@ntut.edu.tw
}

Received 2 April 2013; Revised 27 June 2013; Accepted 3 July 2013

Academic Editor: Mahmoud M. El-Nahass

Copyright (C) 2013 K. I. Hwu et al. This is an open access article distributed under the Creative Commons Attribution License, which permits unrestricted use, distribution, and reproduction in any medium, provided the original work is properly cited.

A photovoltaic energy conversion system, constructed by high step-up converter with hybrid maximum power point tracking (HMPPT), is presented. A voltage converter with a high voltage conversion ratio is proposed, which is simple in circuit and easy in control. After this, such a converter operating with a suitable initial duty cycle of the pulsewidth-modulated (PWM) control signal, together with the proposed HMPPT algorithm combining the fractional open-circuit voltage method and the incremental conductance method, is applied to the photovoltaic energy conversion system. By doing so, not only the maximum power point tracking speed can be increased, but also the oscillation around the maximum power point can be reduced. Aside from these, the field programmable gate array (FPGA) is used as a control kernal of the overall system, so as to realize the HMPPT and fully digitalized control. Finally, via a PV simulator, some experimental results are provided to verify the effectiveness of the proposed photovoltaic energy conversion system.

\section{Introduction}

With energy shortage, the solar cell energy is getting more and more important in the world. The photovoltaic energy conversion system contains the solar array, the power conditioner, the electric box, the transformer, the battery, and so forth. As for the power conditioner, it contains DC-DC converter, DC-AC inverter, and the accompanying controller.

As generally recognized, high step-up converters are widely used in various applications. In the photovoltaic energy conversion system, the high step-up converter takes an important role in boosting voltage from the low level to the high level as well as in executing the maximum power point tracking. Up to the present, there have been many methods to realize high step-up converters. For example, the literatures [1-9] take the coupling inductor methods or the charge pump methods; the literatures [10-14] adopt the energy superposition or even combine the methods mentioned above. However, the literatures [15-27] have individual demerits. In $[9,13]$, the output voltages are floating, thus limiting their industrial applications to some extent. In $[5,9$,
$12,15,26,27]$, the power switches are floating, thereby causing the gate drivers to be isolated and hence the circuit complexity and cost to be increased. In [16-23], the circuit structures are too large, thus causing the corresponding analysis and design to be complicated or the efficiency to be degraded. In $[7,13$, 14], although the circuits are simple and easy to implement, the corresponding voltage conversion ratios are not so high, thereby limiting their industrial applications to some extent. In $[3,15,16,25]$, although the high voltage conversion ratios can be achieved, the high-nonlinear voltage conversion ratios make the systems difficult to control; that is, too many poles and zeros lead to high-order controllers required. As generally recognized, the photovoltaic energy conversion system often uses the battery as a buffer. However, for analysis convenience, the proposed photovoltaic energy conversion system is without the battery and is constructed only by the solar array and the proposed DC-DC converter with the proposed hybrid maximum power point tracking (HMPPT). In the following, the overall system will be described first, and secondly the DC-DC converter will be depicted along with its basic operating principles and small-signal AC model. 


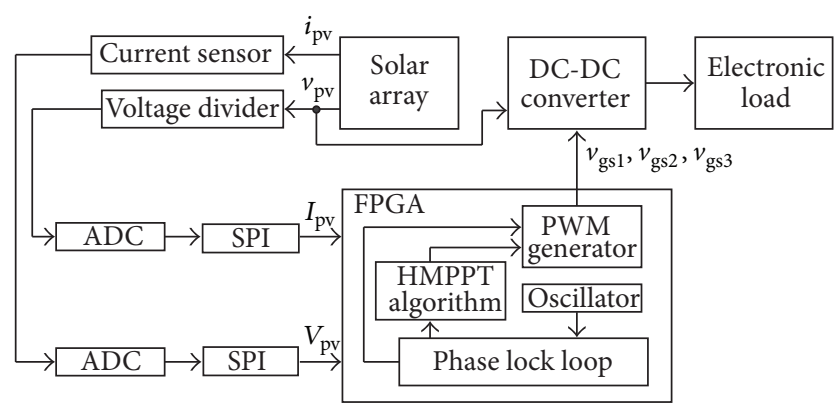

FIgURE 1: Overall system configuration.

After this, the HMPPT algorithm will be shown. Finally, some experimental results will be provided to verify the proposed topology.

\section{Overall System Configuration}

Figure 1 shows the overall system function block diagram, which is constructed mainly by one solar array, one DCDC converter, one FPGA controller with peripheral circuits containing one current sensor, one voltage divider, two ADCs (analog-to-digital converters), and two SPIs (series peripheral interfaces). In FPGA, there are one PWM generator, one HMPPT algorithm, one oscillator, and one phase lock loop. The solar array sends out the voltage to the DC-DC converter as well as to the voltage divider. Such a DC-DC converter is controlled by FPGA via the gate driving signals $v_{\mathrm{gs} 1}, v_{\mathrm{gs} 2}$, and $v_{\mathrm{gs} 3}$, which needs the digital voltage and current signals, $V_{\mathrm{pv}}$ and $I_{\mathrm{pv}}$, coming from the solar array after the current sensor, the voltage divider, ADCs, and SPIs. It is noted that the output of the solar array is replaced by the output of the PV simulator, and the output of the proposed DC-DC converter is sent to the electronic load operating under the constant voltage mode.

Figure 2(a) shows the proposed high step-up converter, which is established by one charge pump, one dual-inductor circuit, one output diode, and one output capacitor. The charge pump is built up by one capacitor $C_{b}$, one diode $D_{b}$, and two switches $S_{1}$ and $S_{2}$, whereas the dual-inductor circuit is constructed by one capacitor $C_{e}$, two diodes $D_{1}$ and $D_{2}$, and two inductors $L_{1}$ and $L_{2}$. By the way, the load is represented by one resistor $R_{L}$. It is noted that $R_{L}$ is used for the convenience of analysis of the behavior of the proposed DC-DC converter but will be replaced by the electronic load for the photovoltaic energy conversion system to be considered.

\section{Proposed High Step-Up Converter}

As generally acknowledged, the solar cell or PV generator is ideally modeled by one current source connected in parallel with one diode. The voltage across the turn-on diode is according to the illumination density. Therefore, in this paper, under a given illumination intensity at the MPP, the maximum output power of the solar cell can be obtained, and hence the corresponding output voltage and current can be known. So, at the MPP, the output voltage of the solar cell can be kept almost constant, whereas, not at the MPP, the output voltage of the solar cell is varied with the output power of the solar cell. However, in general, the DC-DC converter in the photovoltaic energy conversion system is the first stage, whose output voltage is kept constant because the second stage, AC-DC converter, can be designed to have its own input voltage controlled at some value. Consequently, for the convenience of the design and verification of the proposed high step-up converter, this converter is disconnected from the system and verified under the constant input voltage equal to the output voltage of the solar cell at the MPP, along with voltage loop control. After this, the designed converter is connected to the solar cell and controlled based on the proposed hybrid MPPT algorithm.

Prior to going into this section, there are some symbols and assumptions to be given as follows. The input voltage is $v_{i}$, the input current is $i_{i}$, the output voltage is $v_{o}$, the currents flowing through $L_{1}, L_{2}, C_{b}$, and $C_{e}$ are $i_{L_{1}}, i_{L_{2}}, i_{b}$, and $i_{e}$, respectively, and the voltages across switches and diodes during the turn-on period and the blanking times between two MOSFET switches are zero. Besides, since the energytransferring capacitors $C_{b}$ and $C_{e}$, operating based on the charge pump principle, are abruptly charged to some voltages within a very short time which is much less than the switching period $T_{s}$, it is reasonably assumed that the voltage across the capacitor $C_{b}$ is equal to $v_{i}$, and the voltage across the capacitor $C_{e}$ is equal to $2 v_{i}$. Since this converter is also assumed to operate in the continuous conduction mode (CCM), there are two operating states in such a converter. Therefore, the following analyses contain the explanation of the current flow direction in each state, the description of the differential equations, the relationship between DC input voltage $V_{i}$ and DC output voltage $V_{o}$, and the small-signal equations and model.

Under the assumption that the value of $L_{1}$ is equal to that of $L_{2}$, let

$$
\begin{aligned}
& L=L_{1}+L_{2} \\
& i_{L_{1}}=i_{L_{2}}=i
\end{aligned}
$$

3.1. State $1\left(t_{0} \sim t_{1}\right)$. As shown in Figure 2(b), $S_{1}$ and $S_{2}$ are turned on, $S_{3}$ is turned off, $D_{1}$ and $D_{2}$ are forward biased, and $D_{b}$ is reverse biased. Since the voltage across $C_{e}$ is equal to $2 v_{i}, L_{1}$ and $L_{2}$ are to be magnetized. During this state, the output energy required is supplied from $C_{o}, C_{b}$ is discharged, and $C_{e}$ is charged. Therefore, the corresponding differential equations are

$$
\begin{gathered}
L \frac{d i}{d t}=4 v_{i}, \\
C_{o} \frac{d v_{o}}{d t}=-\frac{v_{o}}{R_{L}}, \\
i_{i}=i_{L_{1}}+i_{L_{2}}+i_{e}=2 i+i_{e} .
\end{gathered}
$$




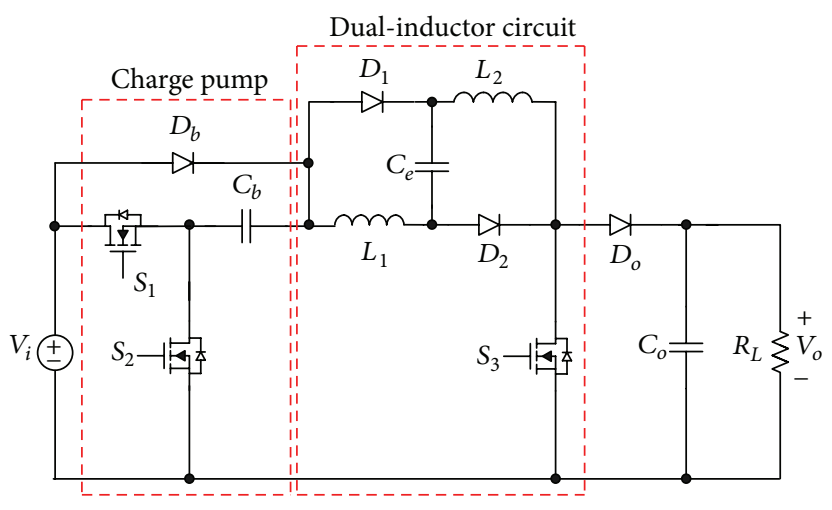

(a)

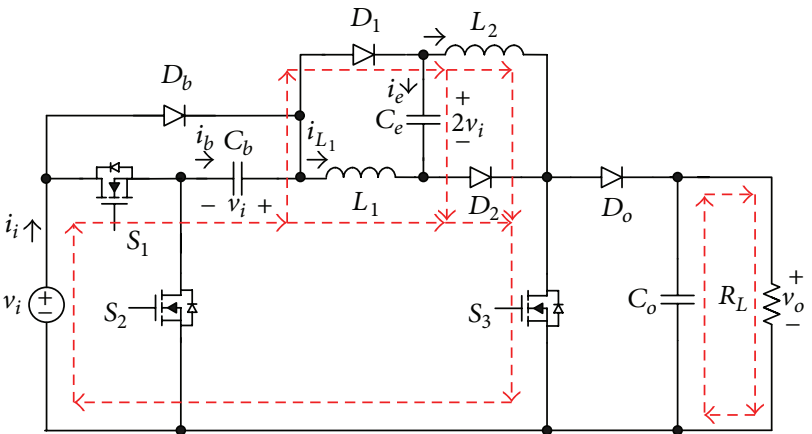

(b)

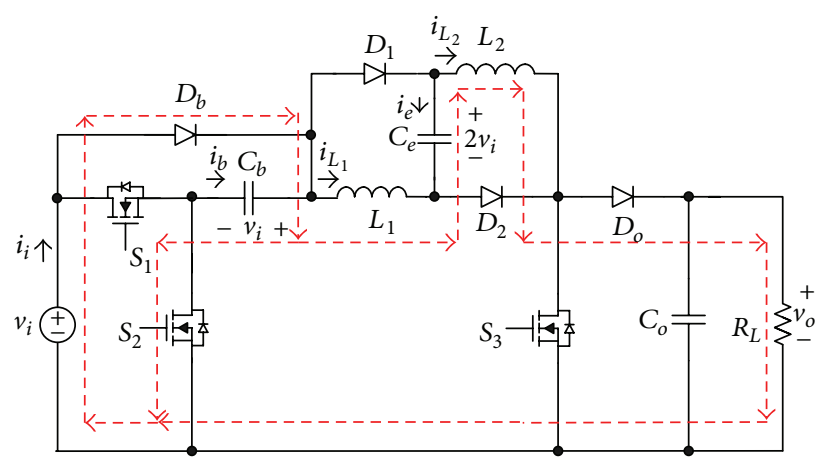

(c)

Figure 2: (a) Proposed high step-up converter; (b) current flow in State 1; (c) current flow in State 2.

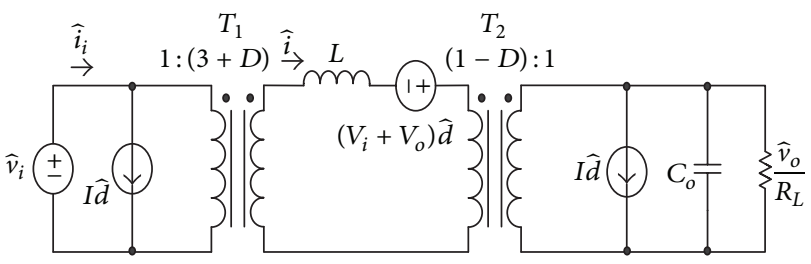

FIGURE 3: Small-signal AC model for the proposed high step-up converter.

3.2. State $2\left(t_{1} \sim t_{0}+T_{s}\right)$. As depicted in Figure 2(c), $S_{1}$ and $S_{2}$ are turned off, $S_{3}$ is turned on, $D_{1}$ and $D_{2}$ are reverse biased, and $D_{b}$ is forward biased. During this state, $v_{i}$ plus $L_{1}$ and $L_{2}$ releases energy to the load, thereby causing $L_{1}$ and $L_{2}$ to be demagnetized. Besides, $C_{b}$ is charged, and $C_{e}$ is discharged. Therefore, the corresponding differential equations are

$$
\begin{gathered}
L \frac{d i}{d t}=3 v_{i}-v_{o}, \\
C_{o} \frac{d v_{o}}{d t}=i-\frac{v_{o}}{R_{L}}, \\
i_{i}=i+i_{b} .
\end{gathered}
$$

Prior to obtaining the average equations from (2) and (3), there is a symbol $\langle y\rangle$ that is used to represent the average value of a variable $y$, where $y$ indicates voltage or current as follows:

$$
\langle y\rangle=\frac{1}{T_{s}} \int_{0}^{T_{s}} y d \tau
$$

According to (2)-(4), the averaged equations can be obtained to be

$$
\begin{gathered}
L \frac{d\langle i\rangle}{d t}=(3+d)\left\langle v_{i}\right\rangle-(1-d)\left\langle v_{o}\right\rangle, \\
C_{o} \frac{d\left\langle v_{o}\right\rangle}{d t}=(1-d)\langle i\rangle-\frac{\left\langle v_{o}\right\rangle}{R_{L}}, \\
\left\langle i_{i}\right\rangle=(1+d)\langle i\rangle+(1-d)\left\langle i_{b}\right\rangle+d\left\langle i_{e}\right\rangle,
\end{gathered}
$$

where $d$ is a variable denoting the duty cycle of the PWM control signal for $Q_{1}$.

Based on the ampere-second balance, $\left\langle i_{e}\right\rangle$ and $\left\langle i_{b}\right\rangle$ can be expressed as a function of $\langle i\rangle$ and a function of $\langle i\rangle$ and $\left\langle i_{e}\right\rangle$, respectively, to be

$$
\left\langle i_{e}\right\rangle=\frac{(1-d)\langle i\rangle}{d}, \quad\left\langle i_{b}\right\rangle=\frac{d\left(2\langle i\rangle+\left\langle i_{e}\right\rangle\right)}{1-d} .
$$



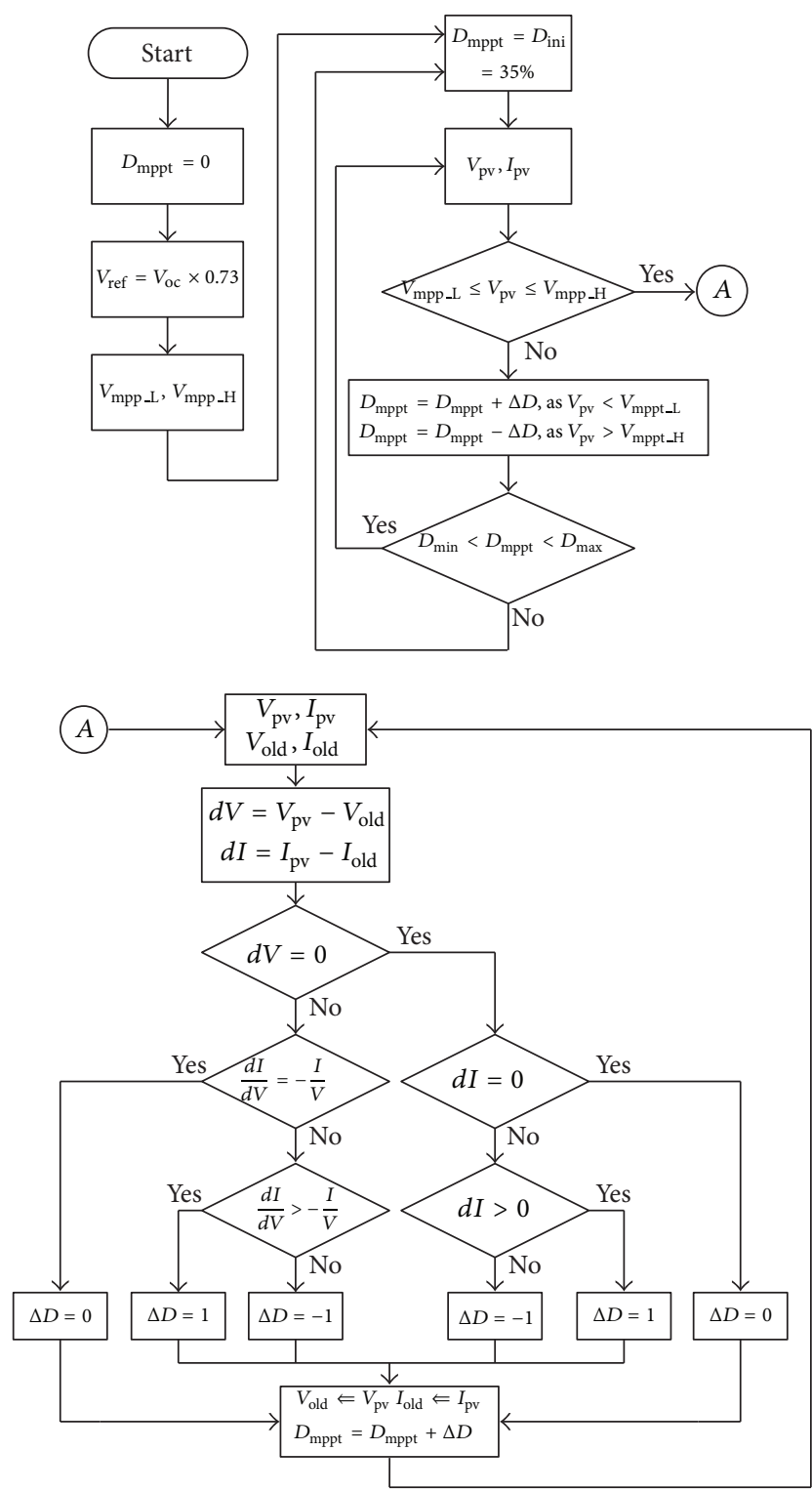

FIGURE 4: Flow chart for the proposed HMPPT.

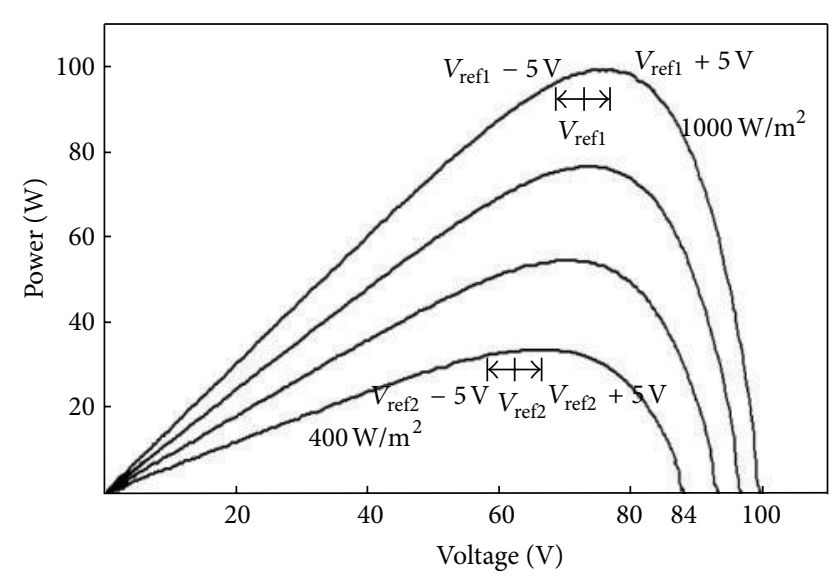

Figure 5: $P-V$ curves obtained from the PV simulator.
And hence, by substituting (6) into (5), (5) can be rewritten as

$$
\begin{gathered}
L \frac{d\langle i\rangle}{d t}=(3+d)\left\langle v_{i}\right\rangle-(1-d)\left\langle v_{o}\right\rangle, \\
C_{o} \frac{d\left\langle v_{o}\right\rangle}{d t}=(1-d)\langle i\rangle-\frac{\left\langle v_{o}\right\rangle}{R_{L}}, \\
\left\langle i_{i}\right\rangle=(3+d)\langle i\rangle .
\end{gathered}
$$

Prior to obtaining the small-signal AC model from (7), the perturbation and linearization of (7) are indispensable. First of all, $\langle y\rangle$ is represented by the corresponding DC quiescent value $Y$ plus the superimposed small $\mathrm{AC}$ variation $\hat{y}$, along with the assumption that $\mathrm{AC}$ variation is small in magnitude compared to the DC quiescent value.

Let

$$
\begin{aligned}
\left\langle v_{i}\right\rangle=V_{i}+\widehat{v}_{i}, & \left|\hat{v}_{i}\right| \ll V_{i}, \\
\left\langle v_{o}\right\rangle=V_{o}+\widehat{v}_{o}, & \left|\widehat{v}_{o}\right| \ll V_{o}, \\
\left\langle i_{i}\right\rangle=I_{i}+\hat{i}_{i}, & \left|\hat{i}_{i}\right| \ll I_{i}, \\
\langle i\rangle=I+\hat{i}, & |\hat{i}| \ll I, \\
d=D+\widehat{d}, & |\hat{d}| \ll D .
\end{aligned}
$$

Next, by substituting (8) into (7), the following equations are obtained:

$$
\begin{gathered}
L \frac{d(I+\hat{i})}{d t}=(3+D+\widehat{d})\left(V_{i}+\widehat{v}_{i}\right)-(1-D-\widehat{d})\left(V_{o}+\widehat{v}_{o}\right), \\
C_{o} \frac{d\left(V_{o}+\widehat{v}_{o}\right)}{d t}=(1-D-\widehat{d})(I+\hat{i})-\frac{\left(V_{o}+\widehat{v}_{o}\right)}{R_{L}}, \\
I_{i}+\widehat{i_{i}}=(3+D+\widehat{d})(I+\widehat{i}) .
\end{gathered}
$$

Consequently, the DC quiescent equations from (9) can be obtained to be

$$
\begin{gathered}
0=(3+D) V_{i}-(1-D) V_{o} \\
0=(1-D) I-\frac{V_{o}}{R_{L}} \\
I_{i}=(3+D) I .
\end{gathered}
$$

And hence, the corresponding voltage conversion ratio of this converter from (10) can be obtained to be

$$
\frac{V_{o}}{V_{i}}=\frac{3+D}{1-D}
$$




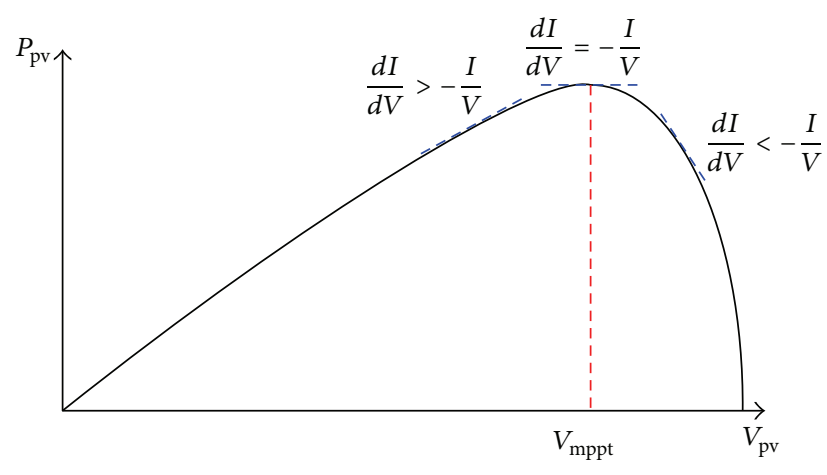

(a)

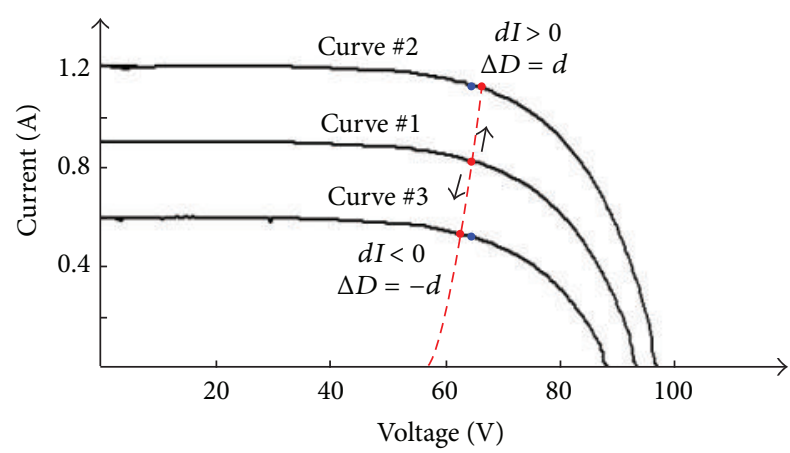

(b)

FIGURE 6: Judgment for the incremental conductance method.

On the other hand, with the second-order AC terms neglected, the small-signal AC equations can be obtained to be

$$
\begin{gathered}
L \frac{d \hat{i}}{d t}=\left(V_{o}+V_{i}\right) \hat{d}+(3+D) \hat{v}_{i}-(1-D) \widehat{v}_{o}, \\
C_{o} \frac{d \widehat{v}_{o}}{d t}=-I \widehat{d}+(1-D) \hat{i}-\frac{\widehat{v}_{o}}{R_{L}}, \\
\widehat{i_{i}}=(3+D) \hat{i}+I \hat{d} .
\end{gathered}
$$

And hence, the resulting small-signal AC model of the proposed high step-up converter is shown in Figure 3 according to (12), where $T_{1}$ and $T_{2}$ are the ideal transformers with the turns ratios of $1:(3+D)$ and $(1-D): 1$, respectively. Accordingly, by taking the Laplace transform of (12), the relationship between $\widehat{v}_{o}(s), \widehat{v}_{i}(s)$, and $\widehat{d}(s)$ can be expressed to be

$$
\widehat{v}_{o}(s)=G_{v g}(s) \widehat{v}_{i}(s)+G_{v d}(s) \widehat{d}(s),
$$

where

$$
\begin{aligned}
G_{v g}(s)= & \left.\frac{\widehat{v}_{o}(s)}{\widehat{v}_{i}(s)}\right|_{\widehat{d}(s)=0}=\frac{(3+D)}{(1-D)} \\
& \times\left[\frac{1}{1+s\left(L /(1-D)^{2} R_{L}\right)+s^{2}\left(L C_{o} /(1-D)^{2}\right)}\right],
\end{aligned}
$$

$$
\begin{aligned}
G_{v d}(s)= & \left.\frac{\widehat{v}_{o}(s)}{\widehat{d}(s)}\right|_{\widehat{v}_{i}(s)=0}=\frac{\left(V_{o}+V_{i}\right)}{(1-D)} \\
& \times\left[\frac{1-s\left(L I /(1-D)\left(V_{o}+V_{i}\right)\right)}{1+s\left(L /(1-D)^{2} R_{L}\right)+s^{2}\left(L C_{o} /(1-D)^{2}\right)}\right],
\end{aligned}
$$

where $G_{v g}(s)$ is the input-to-output transfer function and $G_{v d}(s)$ is the control-to-output transfer function. From (15), it can be seen that the proposed converter has one right halfplane zero.

\section{Hybrid Maximum Power Point Tracking}

The proposed HMPPT algorithm combines the incremental conductance method and the fractional open-circuit voltage method, so as to reduce the required time between the startup and the maximum power point as well as to remove the perturbation on the PV output voltage at the maximum power point. As shown in Figure 4, the duty cycle of the pulsewidth-modulated (PWM) control signal, $D_{\text {mppt }}$, is set to zero first so as to obtain the open voltage $V_{\mathrm{oc}}$ from the PV simulator. After this, such a value is multiplied by the value of $k$ so as to obtain the voltage reference $V_{\text {ref }}$, which is used to determine which method is adopted. Above all, since the left side of the maximum power point has the slower slope than the right side of the maximum power point, the maximum power point tracking gets started from the left side of the maximum power point with $D_{\text {mppt }}$ set to an initial value of $D_{\text {ini }}$, which is close to the duty cycle which lets the proposed high step-up converter work under the rated output voltage. By doing so, the maximum power point can be stably and fast tracked. The corresponding basic operating principles are to be described in details as follows.

As shown in Figure 5, the $P-V$ curves outputted from the PV simulator are taken into account. Therefore, let the voltage references $V_{\text {ref1 }}$ and $V_{\text {ref2 }}$ for the maximum illuminance and the minimum illuminance, respectively, fall on the left sides of the individual maximum power points. Accordingly, the value of $k$ is set at 0.73 . Hence, the lower bound value $V_{\text {mppt_L }}$ and the upper bound value $V_{\text {mppt_H }}$ correspond to $V_{\text {ref2 }}$ minus $5 \mathrm{~V}$ and $V_{\text {ref1 }}$ plus $5 \mathrm{~V}$, respectively. If the tracking point falls within the interval between $V_{\text {mppt.L }}$ and $V_{\text {mppt_H}}$, then the HMPPT algorithm is changed from the fractional open-circuit voltage method to the incremental conductance method. If the digital voltage signal $V_{\mathrm{pv}}$ below $V_{\text {mppt_L }}$, then the duty cycle of PWM control signal, $D_{\text {mmpt }}$, is increased by the incremental value $\Delta D$, where $\Delta D$ is set to one. If $V_{\mathrm{pv}}$ beyond $V_{\text {mppt_H }}$, then $D_{\text {mmpt }}$ is decreased by $\Delta D$, where $\Delta D$ is also set to one. It is noted that if the interval between $V_{\text {mppt_L }}$ and $V_{\text {mppt_H }}$ is too large, then the voltage outputted from the PV simulator, $v_{\mathrm{pv}}$, is far from the maximum power point; otherwise, it is close to the maximum power point. 


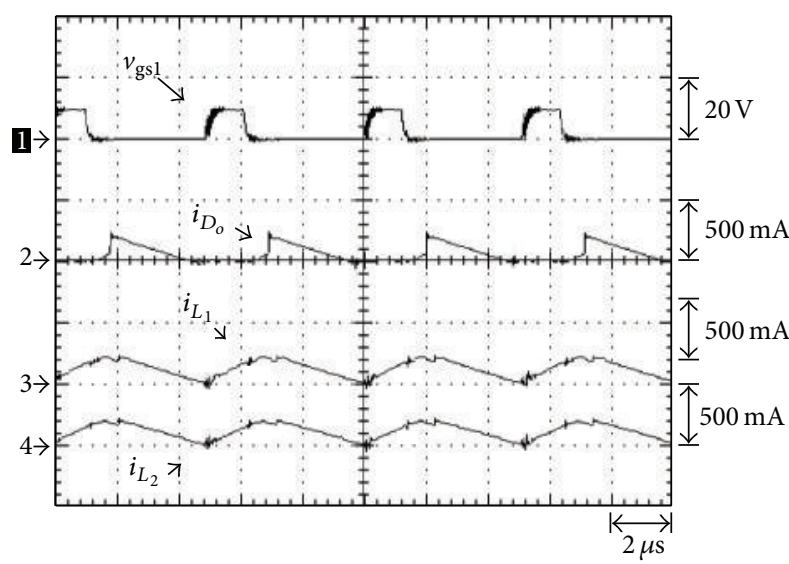

(a)

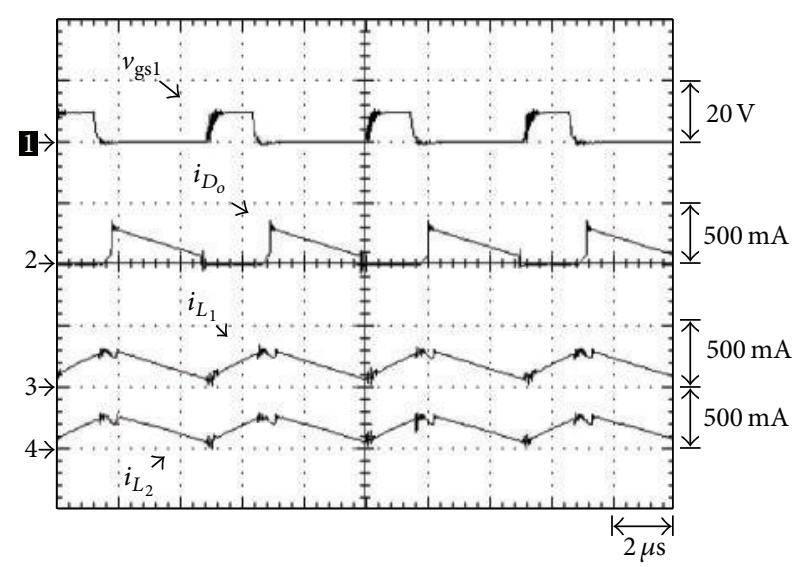

(b)

FIGURE 7: Measured waveforms: (a) $25 \%$ load-(1) $v_{\mathrm{gs} 1}$; (2) $i_{D o}$; (3) $i_{L_{1}}$; (4) $i_{L_{2}}$. (b) $50 \%$ load-(1) $v_{\mathrm{gs} 1}$; (2) $i_{D o}$; (3) $i_{L_{1}}$; (4) $i_{L_{2}}$.

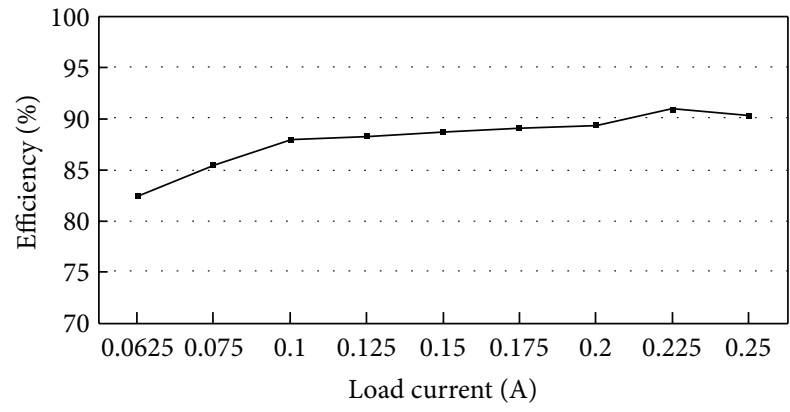

Figure 8: Efficiency versus load current.

Furthermore, in order to make $v_{\mathrm{pv}}$ reach the maximum power point as soon as possible, $D_{\text {mmpt }}$ is initially set to $D_{\text {ini }}$ of 0.35 , which is close to the duty cycle of the proposed high step-up converter operating under the rated output voltage. Furthermore, the minimum duty cycle $D_{\min }$ is $25 \%$ and the maximum duty cycle $D_{\max }$ is $45 \%$. If $D_{\text {mmpt }}$ is below $D_{\min }$ or above $D_{\max }$, then $D_{\text {mmpt }}$ will be set to $D_{\text {ini }}$ and the algorithm will go ahead from this; otherwise, the values of $V_{\mathrm{pv}}$ and $I_{\mathrm{pv}}$ will be updated and the algorithm will go ahead from this.

Once $V_{\mathrm{pv}}$ falls between $V_{\text {mmpt. }}$ and $V_{\text {mmpt H }}$, the tracking point enters into the incremental conductance region. Accordingly, whether the voltage difference between $V_{\mathrm{pv}}$ and $V_{\text {old }}, d V$, is zero or not will be checked first so as to avoid the denominator of the current difference between $I_{\mathrm{pv}}$ and $I_{\text {old }}$, $d I$, over $d V$ being zero, where $V_{\text {old }}$ and $I_{\text {old }}$ are the previous values of $V_{\mathrm{pv}}$ and $I_{\mathrm{pv}}$, respectively.

From Figures 4 and 6(a), as $d V$ is not zero, the relationship between $d I / d V$ and minus conductance, $-I / V$, is used to determine whether $D_{\mathrm{mmpt}}$ is increased or not. If $d I / d V$ is equal to $-I / V$, then $\Delta D$ is zero, implying the tracking point is stabilized at the maximum power point. If $d I / d V$ is larger than $-I / V$, then $D_{\text {mmpt }}$ is increased by one; otherwise $D_{\text {mmpt }}$ is decreased by one.

From Figures 4 and 6(b), as $d V$ is zero, $d I$ is used to determine whether $D_{\text {mmpt }}$ is increased or not. If $d I$ is zero,
TABLE 1: CSSS-100 solar array specifications.

\begin{tabular}{lc}
\hline Item & Value \\
\hline Max. power $\left(P_{\max }\right)$ & $100 \mathrm{~W}$ \\
Max. power voltage $\left(V_{\mathrm{mp}}\right)$ & $76 \mathrm{~V}$ \\
Max. power current $\left(I_{\mathrm{mp}}\right)$ & $1.32 \mathrm{~A}$ \\
Open Voltage $\left(V_{\mathrm{oc}}\right)$ & $100 \mathrm{~V}$ \\
Short current $\left(I_{\mathrm{sc}}\right)$ & $1.65 \mathrm{~A}$ \\
\hline
\end{tabular}

TABLE 2: Converter specifications.

\begin{tabular}{lc}
\hline Item & Value \\
\hline Rated input voltage $\left(V_{i}\right)$ & $76 \mathrm{~V}$ \\
Rated output voltage $\left(V_{o}\right)$ & $400 \mathrm{~V}$ \\
Rated output current $\left(I_{o}\right)$ & $1.32 \mathrm{~A}$ \\
Switching frequency $\left(f_{s}\right)$ & $200 \mathrm{kHz}$ \\
\hline
\end{tabular}

then $\Delta D$ is zero. In Figure 6(b), as the $I-V$ curve is changed from curve 1 to curve $2, d I$ is positive, implying that the tracking point is on the left side of the maximum power point and hence increasing $D_{\text {mmpt }}$ by one; as the $I-V$ curve is changed from curve 1 to curve $3, d I$ is negative, implying the tracking point is on the right side of the maximum power point and hence decreasing $D_{\text {mmpt }}$ by one. After this, $V_{\text {old }}$ and $I_{\text {old }}$ are both set to $V_{\mathrm{pv}}$ and $I_{\mathrm{pv}}$, respectively.

\section{Experimental Results}

Prior to this section, there are some specifications to be given. Table 1 shows CSSS-100 solar array specifications, which the PV simulator will be used to construct the simulation environment. Table 2 shows the proposed converter specifications. Table 3 shows the component specifications.

Before verification of the proposed HMPPT, there are some experimental results to be given on the condition that the proposed converter is disconnected from the solar cell system with the input voltage of $76 \mathrm{~V}$. Figure 7(a) shows the gate driving signal for $S_{1}, v_{\mathrm{gs} 1}$, the current in $D_{o}, i_{D o}$, 


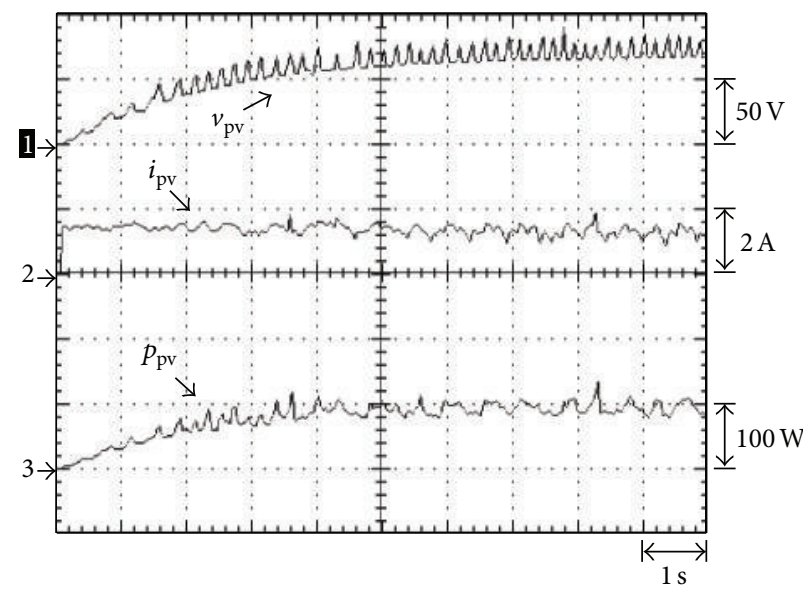

(a)

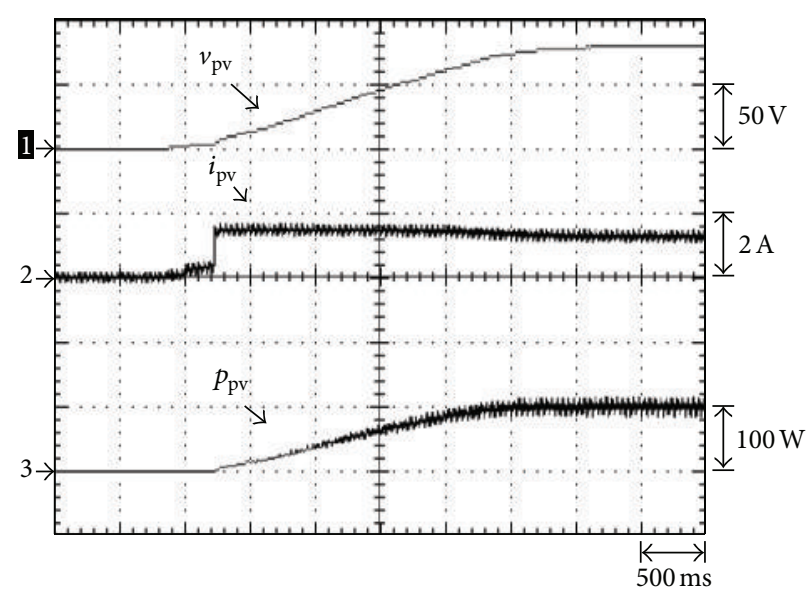

(b)

FIGURE 9: Startup waveforms under $1000 \mathrm{~W} / \mathrm{cm}^{2}$ illumination intensity: (a) based on the perturbation and observation method-(1) $v_{\text {pv }}$; (2) $i_{\mathrm{pv}} ;$ (3) $p_{\mathrm{pv}}$ (b) Based on the proposed HMPPT method-(1) $v_{\mathrm{pv}} ;(2) i_{\mathrm{pv}} ;$ (3) $p_{\mathrm{pv}}$.

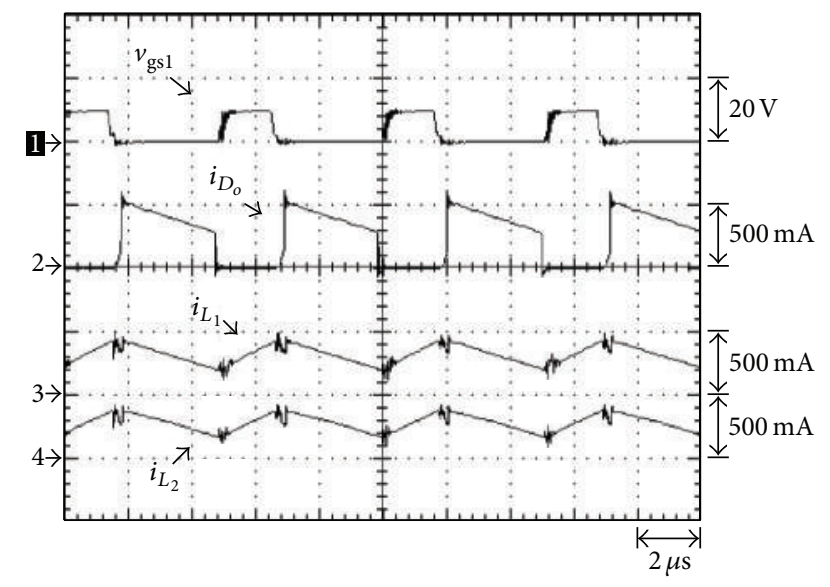

FIGURE 10: Measured waveforms for the proposed converter with the proposed HMPPT method applied under illumination intensity of $1000 \mathrm{~W} / \mathrm{cm}^{2}:$ (1) $v_{\mathrm{gsl}} ;$; (2) $i_{D o}$; (3) $i_{L_{1}}$; (4) $i_{L_{2}}$.

TABLE 3: Component specifications.

\begin{tabular}{lc}
\hline Component & Value/product name \\
\hline$L_{1}$ and $L_{2}$ & $1.4 \mathrm{mH}$ \\
$C_{b}$ and $C_{e}$ & $220 \mu \mathrm{F} / 220$ V Electrolytic Capacitor \\
$C_{o}$ & $220 \mu \mathrm{F} / 450$ V Electrolytic Capacitor \\
$S_{1}$ and $S_{2}$ & FQA55N25 \\
$S_{3}$ & SPP20N60C3 \\
$D_{1}$ and $D_{2}$ & SFF1008G \\
$D_{o}$ & STTH12R06D \\
ADC & ADCS7476 \\
FPGA & EP1C3T100C8N \\
\hline
\end{tabular}

the current in $L_{1}, i_{L_{1}}$, and the current in $L_{2}, i_{L_{2}}$, at $25 \%$ of the rated load, whereas Figure $7(\mathrm{~b})$ shows the gate driving signal for $S_{1}, v_{\mathrm{gs} 1}$, the current in $D_{o}, i_{D o}$, the current in $L_{1}, i_{L_{1}}$, and the current in $L_{2}, i_{L_{2}}$, at $50 \%$ of the rated load. From these results, it can be seen that the proposed converter can operate stably. In addition, Figure 8 shows the curve of efficiency versus load current. From Figure 8, it can be seen that the efficiency is above $82.5 \%$ all over the load range and can be up to $91 \%$.

In the following, the solar array is implemented by the PV simulator named PVS01203. Based on such a simulator, different illumination intensity levels are given to verify the proposed HMPPT algorithm.

For the perturbation and observation method to be applied, under illumination intensity of $1000 \mathrm{~W} / \mathrm{cm}^{2}$, Figure 9(a) shows the output voltage from the PV simulator, $v_{\mathrm{pv}}$, the output current from the PV simulator, $i_{\mathrm{pv}}$, and the output power from the PV simulator, $p_{\mathrm{pv}}$. For the proposed method to be applied, under illumination intensity of $1000 \mathrm{~W} / \mathrm{cm}^{2}$, Figure 9 (b) shows the output voltage from the PV simulator, $v_{\mathrm{pv}}$, the output current from the PV simulator, $i_{\mathrm{pv}}$, and the output power from the PV simulator, $p_{\mathrm{pv}}$. From these results, it can be seen that the setting time for the perturbation and observation method is about $6 \mathrm{~s}$ and the setting time for the proposed method is about $2.8 \mathrm{~s}$, and this demonstrates that the proposed method has a faster tracking speed than the perturbation and observation method. Also, there is no perturbation on $v_{\mathrm{pv}}$ at the maximum power point in the latter. In addition, under illumination intensity of $1000 \mathrm{~W} / \mathrm{cm}^{2}$ with the proposed HMPPT method, Figure 10 shows the gate driving signal for $S_{1}, v_{\mathrm{gs} 1}$, the current in $D_{o}, i_{D o}$, the current in $L_{1}, i_{L_{1}}$, and the current in $L_{2}, i_{L_{2}}$. From Figure 10, it can be seen that the proposed converter can operate stably.

On the other hand, Figures 11(a) to 11(c) show the maximum power point tracking in the PV simulator under three illumination intensity levels of $1000 \mathrm{~W} / \mathrm{m}^{2}, 800 \mathrm{~W} / \mathrm{m}^{2}$, and $600 \mathrm{~W} / \mathrm{m}^{2}$, respectively. From these, it can be seen that the 


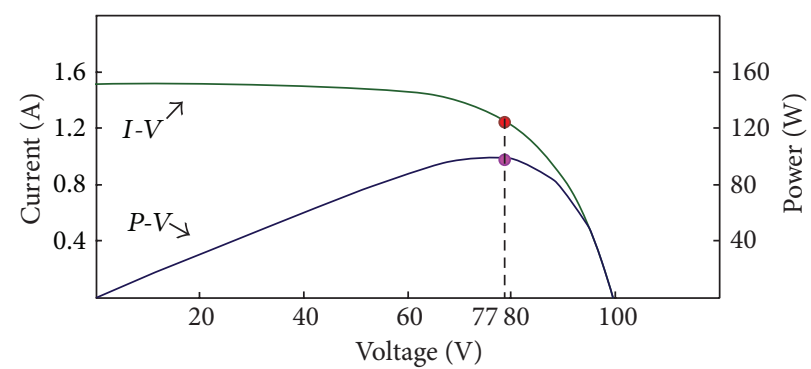

(a)

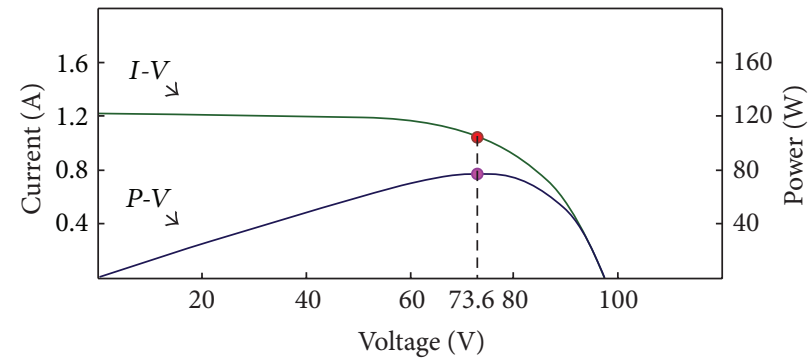

(b)

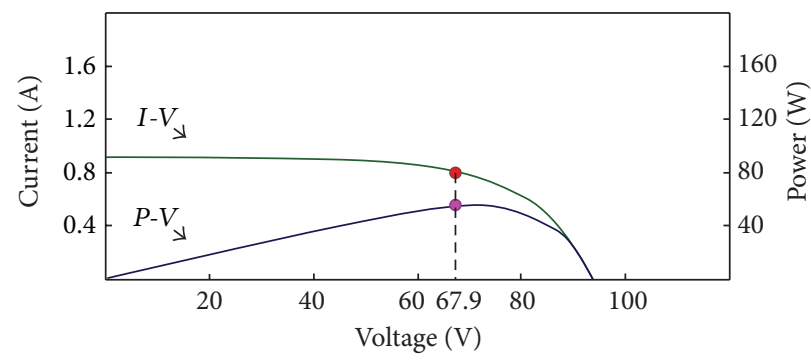

(c)

Figure 11: $P-V$ and $I-V$ curves based on the proposed HMPPT method under illumination intensity: (a) $1000 \mathrm{~W} / \mathrm{cm}^{2}$; (b) $800 \mathrm{~W} / \mathrm{cm}^{2}$; (c) $600 \mathrm{~W} / \mathrm{cm}^{2}$.

proposed method can track the maximum power point under different illumination intensity levels.

\section{Conclusions}

In this paper, a high step-up converter and an HMPPT algorithm combining the fractional open-circuit voltage method and the incremental conductance method are presented and applied to a photovoltaic energy conversion system. Based on the PV simulator, the proposed converter and algorithm can be demonstrated via some experimental results, so as to reduce the time slap of the maximum power point tracking at startup as well as to obtain no perturbation on the PV output voltage at the maximum power point. Besides, based on digital control, the converter control and the HMPPT algorithm are quite easy to implement.

\section{References}

[1] C.-T. Pan and C.-M. Lai, "A high-efficiency high step-up converter with low switch voltage stress for fuel-cell system applications," IEEE Transactions on Industrial Electronics, vol. 57, no. 6, pp. 1998-2006, 2010.

[2] S.-Y. Tseng, C.-L. Ou, S.-T. Peng, and J.-D. Lee, "Interleaved coupled-inductor boost converter with boost type snubber for PV system," in Proceedings of the IEEE Energy Conversion Congress and Exposition (ECCE '09), pp. 1860-1867, September 2009.

[3] R. J. Wai and C. Y. Lin, "High-efficiency, high-step-up DC-DC convertor for fuel-cell generation system," IEE Proceedings of Electric Power Applications, vol. 152, no. 5, pp. 1371-1378, 2005.

[4] W. Li and X. He, "ZVT interleaved boost converters for highefficiency, high step-up DC-DC conversion," IET Electric Power
Applications, vol. 1, no. 2, pp. 284-290, 2007.

[5] R.-J. Wai and R.-Y. Duan, "High-efficiency bidirectional converter for power sources with great voltage diversity," IEEE Transactions on Power Electronics, vol. 22, no. 5, pp. 1986-1996, 2007.

[6] R.-J. Wai and R.-Y. Duan, "High step-up coupled-inductorbased converter using bi-direction energy transmission," in Proceedings of the IEEE Power Electronics Specialists Conference (PESC '05), pp. 406-412, 2005.

[7] J.-W. Back, M.-H. Ryoo, T.-J. Kim, D.-W. Yoo, and J.-S. Kim, "High boost converter using voltage multiplier," in Proceedings of the 31st Annual Conference of IEEE Industrial Electronics Society (IECON '05), pp. 567-572, November 2005.

[8] W. Li, J. Shi, M. Hu, and X. He, "An isolated interleaved activeclamp ZVT flyback-boost converter with coupled inductors," in Proceedings of the European Conference on Power Electronics and Applications (EPE '07), pp. 1-9, September 2007.

[9] Q. Zhao and F. C. Lee, "High-efficiency, high step-up dc-dc converters," IEEE Transactions on Power Electronics, vol. 18, no. 1, pp. 65-73, 2003.

[10] S. Dwari and L. Parsa, "An efficient high-step-up interleaved DC-DC converter with a common active clamp," IEEE Transactions on Power Electronics, vol. 26, no. 1, pp. 66-78, 2011.

[11] Y. Park, S. Choi, W. Choi, and K.-B. Lee, "Soft-switched interleaved boost converters for high step-up and high-power applications," IEEE Transactions on Power Electronics, vol. 26, no. 10, pp. 2906-2914, 2011.

[12] C.-M. Hong, L.-S. Yang, T.-J. Liang, J.-F. Chen, and K. Lee, "Novel bidirectional DC-DC converter with high step-up/down voltage gain," in Proceedings of the IEEE Energy Conversion Congress and Exposition (ECCE '09), pp. 60-66, September 2009.

[13] L.-S. Yang, T.-J. Liang, and J.-F. Chen, "Transformerless DC-DC converters with high step-up voltage gain," IEEE Transactions on Industrial Electronics, vol. 56, no. 8, pp. 3144-3152, 2009. 
[14] B. Axelrod, Y. Berkovich, and A. Ioinovici, "Switched-capacitor/ switched-inductor structures for getting transformerless hybrid DC-DC PWM converters," IEEE Transactions on Circuits and Systems I, vol. 55, no. 2, pp. 687-696, 2008.

[15] B. R. Lin, J. J. Chen, and F. Y. Hsieh, "Analysis and implementation of a bidirectional converter wtthffigh conversion ratio," in Proceedings of the IEEE International Conference on Industrial Technology (ICIT '08), pp. 1-6, April 2008.

[16] S.-Y. Tseng, S.-H. Tseng, and J. G. Huang, "High step-up converter with partial energy processing for livestock stunning applications," in Proceedings of the 21st Annual IEEE Applied Power Electronics Conference and Exposition (APEC '06), pp. 1537-1543, March 2006.

[17] S.-K. Changchien, T.-J. Liang, J.-F. Chen, and L.-S. Yang, "Novel high step-up DCDC converter for fuel cell energy conversion system," IEEE Transactions on Industrial Electronics, vol. 57, no. 6, pp. 2007-2017, 2010.

[18] R. N. A. L. Silva, G. A. L. Henn, P. P. Praça, R. A. da Câmara, L. H. S. C. Barreto, and D. S. Oliveira Jr., "Soft-switching interleaved boost converter with high voltage gain applied to a photovoltaic system," in Proceedings of the IEEE International Symposium on Industrial Electronics (ISIE '10), pp. 1083-1087, July 2010.

[19] S.-K. Changchien, T.-J. Liang, J.-F. Chen, and L.-S. Yang, "Stepup DC-DC converter by coupled inductor and voltage-lift technique," IET Power Electronics, vol. 3, no. 3, pp. 369-378, 2010.

[20] W. Li and X. He, "High step-up soft switching interleaved boost converters with cross-winding-coupled inductors and reduced auxiliary switch number," IET Power Electronics, vol. 2, no. 2, pp. 125-133, 2009.

[21] J.-H. Lee, J.-H. Kim, C.-Y. Won, S.-J. Jang, and Y.-C. Jung, "Soft switching multi-phase boost converter for photovoltaic system," in Proceedings of the 13th International Power Electronics and Motion Control Conference (EPE-PEMC '08), pp. 1924-1928, September 2008.

[22] S.-Y. Tseng, J.-Z. Shiang, W.-S. Jwo, and C.-M. Yang, "Active clamp interleaved boost converter with coupled inductor for high step-up ratio application," in Proceedings of the 7th International Conference on Power Electronics and Drive Systems (PEDS '07), pp. 1394-1400, November 2007.

[23] G. V. Torrico-Bascopé, R. P. Torrico-Bascopé, D. S. Oliveira Jr., F. L. M. Antunes, S. V. Araújo, and C. G. C. Branco, "A generalized high voltage gain boost converter based on three-state switching cell," in Proceedings of the 32nd Annual Conference on IEEE Industrial Electronics (IECON '06), pp. 1927-1932, November 2006.

[24] R. J. Wai and R. Y. Duan, "High-efficiency DC/DC converter with high voltage gain," IEE Proceedings-Electric Power Applications, vol. 152, no. 4, pp. 793-802, 2005.

[25] S. Dwari and L. Parsa, "An efficient high-step-up interleaved DC-DC converter with a common active clamp," IEEE Transactions on Power Electronics, vol. 26, no. 1, pp. 66-78, 2011.

[26] K.-B. Park, G.-W. Moon, and M.-J. Youn, "Nonisolated high step-up stacked converter based on boost-integrated isolated converter," IEEE Transactions on Power Electronics, vol. 26, no. 2, pp. 577-587, 2011.

[27] K. I. Hwu and Y. T. Yau, "High step-up converter based on charge pump and boost converter," IEEE Transactions on Power Electronics, vol. 27, no. 5, pp. 2484-2494, 2012. 

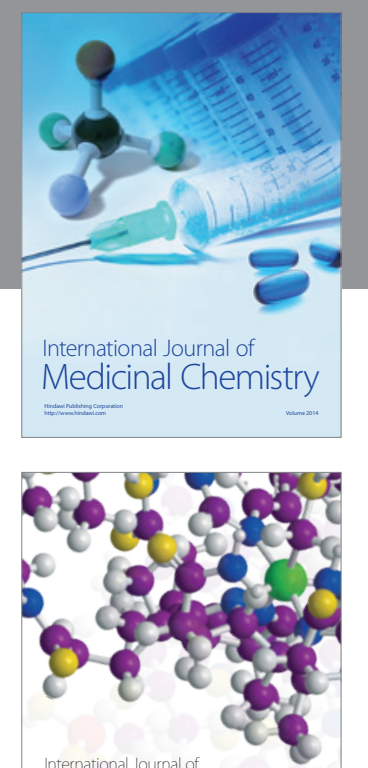

\section{Carbohydrate} Chemistry

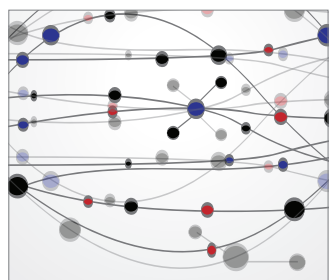

The Scientific World Journal
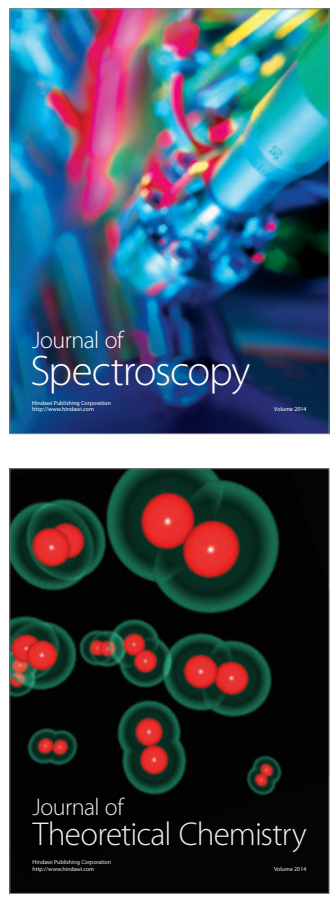
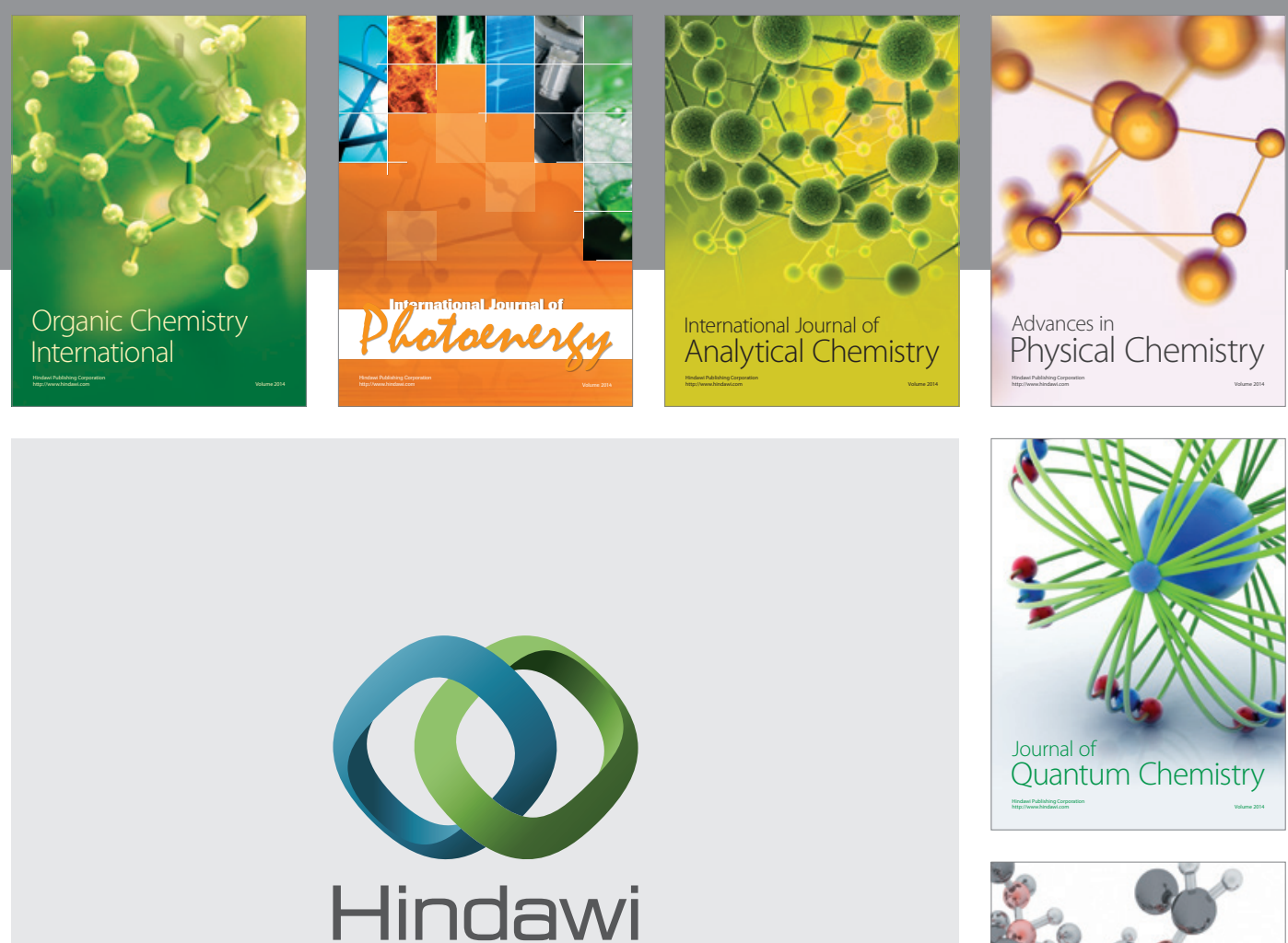

Submit your manuscripts at

http://www.hindawi.com

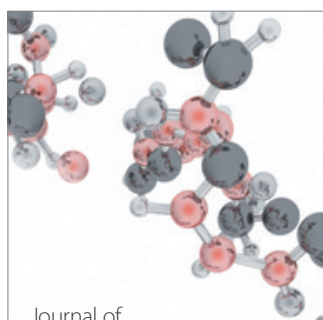

Analytical Methods

in Chemistry

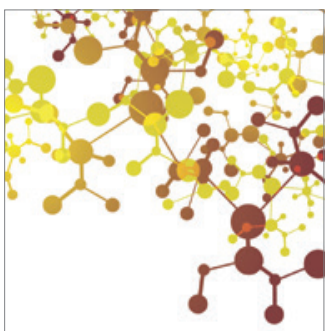

Journal of

Applied Chemistry

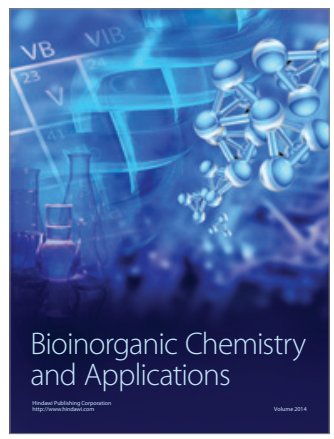

Inorganic Chemistry
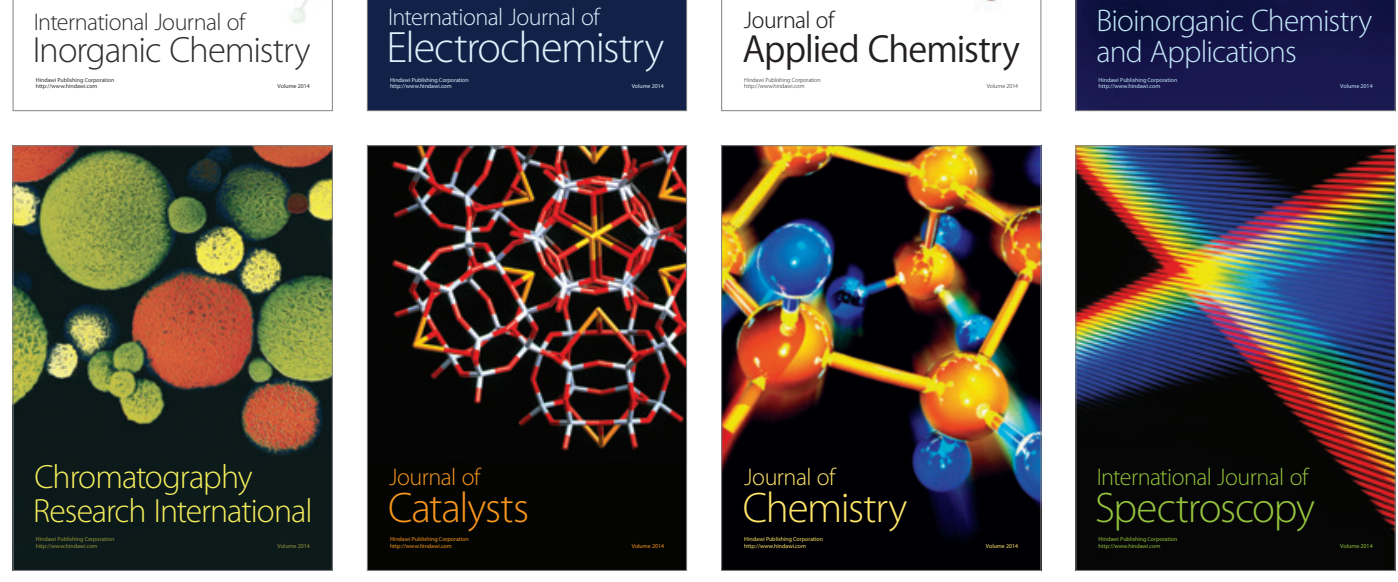